\title{
Rosenberg Self-Esteem Scale Greek Validation on Student Sample
}

\author{
Christina Galanou*, Michael Galanakis, Evangelos Alexopoulos, Christina Darviri \\ Stress Management and Health Promotion, Medicine School, University of Athens, Athens, Greece \\ Email: stressmasterssubmissions@yahoo.gr
}

Received 28 March 2014; revised 22 April 2014; accepted 21 May 2014

Copyright (C) 2014 by authors and Scientific Research Publishing Inc.

This work is licensed under the Creative Commons Attribution International License (CC BY). http://creativecommons.org/licenses/by/4.0/

(c) (i) Open Access

\section{Abstract}

This paper presents the standardization of the Rosenberg Self-Esteem Scale (RSES) in the Greek population. Self-esteem is defined as the positive or negative reflection that the individual has for himself/herself and the belief of being able to cope with the basic challenges of life. The RSES was completed by university students with a mean age of 19 . Along with the RSES we administered the Health Locus of Control Scale, the Perceived Stress Scale (PSS), the Stress and Personality Self Test and the self-esteem questionnaire (Darviri \& Varvogli). The results on the reliability and validity of the RSES were satisfactory as the internal reliability index crombach a was .80 and the RSES had positive statistical significant relationship with the second questionnaire of self-esteem. We also found statistically significant relationships with stress levels, health locus of control and personality types. It seems that when people attribute their good health to others, they have increased self-esteem in relation to people who attributed their good health to themselves. Furthermore our study showed that women have higher levels of self-esteem than men, an opposite outcome to the one of previous validations. The RSES Greek version is a tool that can be used for the measurement of Self-Esteem in the Greek Population.

\section{Keywords}

Self-Esteem, Validation RSES, Stress, Health Locus of Control, AB Personality Types

\section{Introduction}

Nowadays more and more researchers choose to work on self-esteem, as it seems to affect the performance of individuals in various fields and it is part of the psychological portrait (Marsh, 1990). According to Rosenberg (1960), self-esteem is the positive or negative attitude toward the self. It is part of self-concept which is the sum

\footnotetext{
${ }^{*}$ Corresponding author.
} 
of a person's thoughts and emotions when seeing him as the object. Other researchers believe that self-esteem is the emotional evaluation of the person's own value, that is, the individual's judgment of himself. Self-esteem induces feelings-beliefs (I am capable of) and emotions such as triumph, despair, pride and shame (Hewitt, 2009).

According to Smith \& Mackie (2007), self-concept is what we think about ourselves, while self-esteem is the positive or negative evaluation of oneself and how we feel about it. Olsen, Breckler, \& Wiggins (2008) make a different reference to self-esteem indicating that it is the disposition of the person, which represents the judgment of his own merit.

It is also known as the dimension of self-evaluation that contains feelings of value, pride and frustration (Newman \& Newman, 1975) and is inseparable from self-consciousness (Schacter, Gilbert, \& Wegner, 2010).

In the mid 60ies, Rosenberg and other social theorists (Baumeister, Smart, \& Boden, 1996) have defined self-esteem as a personal value. Moreover, Branden (1969) said that self-esteem is the experience of being able to cope with the basic challenges of life and be worthy of happiness. He also mentions that self-esteem is the set of self-confidence, a sense of personal competence and self-respect, and a sense of personal value. All people have the ability to face the various challenges of life, to understand and solve problems, and the right to acquire happiness and respect from others (Branden, 2001).

Maslow (1987) adds that mental health cannot be achieved if the central core of the individual, has not been accepted, loved, respected by others and by himself. Self-esteem, thus, allows people to face life with more confidence, kindness, optimism, and aspects that lead on setting and achieving one's objectives. It also allows individuals to be more ambitious, without having success as their main goal, but every experience is lived, emotional, spiritual or creative. Understanding that self-esteem is important, its development increases the individuals' ability to treat with respect and goodwill to others as well as to acquire good interpersonal relationships while avoiding the destructive ones. Finally, it appears that self-esteem in the workplace enhances creativity.

\section{Self-Esteem Measurement Tool}

The most popular tool for measuring self-esteem is the Rosenberg Self-Esteem Scale (RSES), (1965). It is a one-dimensional tool which concentrates on the perception of self-esteem an individual has for their own value. The questionnaire consists of 10 questions, 5 positive and 5 negative graded statements. It has been translated in many languages, including Farsi, Spanish, French, Chinese, Italian, Estonian and Portuguese. A survey in 53 countries in which this questionnaire was used, showed that the scale presents problems in its one-dimensional structure, as it seems to not only measure self-esteem (Schnitt \& Allik, 2005). Hensley \& Roberts (1976) encountered the same problem in 1976, but found a two factor solution, so that the scale measures a single dimension, self-esteem.

Wang, Siegal, Falck, \& Carlson (2001), show the scale as one-dimensional, but use in their analysis only the positive graded questions. Other researchers indicate that better results can be attributed solely by measuring the negative questions (Crowyn, 2000; Gana, Alaphilippe, \& Bailo, 2005; Marsh, 1996; Motl \& DiStefano, 2002). Finally Greenberger, Chen, Dimitrieva, \& Farruggia (2003) argue that the best results of analysis of the scale can be attributed with two factors, namely positive and negative graded questions.

\section{Relationship of Self-Esteem between Personality, Stress and Health Locus of Control}

Our research will focus on self-esteem and validation of the RSES. For best results we also administered questionnaires of other factors that appear to affect self-esteem, such as stress, health locus of control and personality types.

\subsection{Stress}

The term stress was used by Cannon (1926), indicating that stress is the disruption of homeostasis. Homeostasis is the balance of the body that is when a person is stressed his balance is disturbed, as the body reacts to the stressful stimuli. The factors that threaten homeostasis vary between them, from environmental changes until the physical threat someone may receive. In these cases of threat, the body prepares to react (fight or flight). It concentrates power and energy to meet the challenge (Mash \& Johnston, 1983). A survey of Mash and Johnston 
(1983) showed that parents who experienced stress due to over-active children had lower self-esteem than parents with children who were not hyperactive. Willburn and Smith (2005) who measured the negative life events with self-esteem found similar results. People who had recently experienced stressful situations had lower self-esteem than those who had experienced stressful life events earlier in life. Another research of Kliewer and Sandler (1992) concerning self-esteem, stress and locus of control showed that girls who had an external locus of control and low self-esteem showed greater difficulties in psychological adaptation.

\subsection{Health Locus of Control}

Health locus of control represents the degree of personal responsibility on health outcomes. It is categorized in external and internal factors that affect health such as luck, the doctors or us respectively. It is linked to quality of life, to our subjective sense of well-being and to behaviors associated with health such as smoking and proper nutrition. HLC seems to be the key element for the overall health and wellness (Friedman \& Roseman, 1959). Surveys show that people who believe that external factors are responsible for the good or bad outcome of their health, experience more stress than those who attribute good health to internal factors (Abouserie, 1994).

\subsection{Personality}

In 1950 for the first time appeared two personality types, a theory which describes two common but contradictory personality types. These are two behavioral patterns that can increase or decrease the chances of developing heart disease. They are called type A and type B. Type A is described as hostile, impatient and competitive, and therefore has greater chances of developing heart disease, while type B is more calm and less likely to develop heart problems (Carlson et al., 2007). From the literature review we can see that the personality types are coresponsible along with stress on the occurrence of various diseases. The research of Grossarth-Maticek, Eysenck, and Vetter (1988), showed that people's personality and stress are risk factors for cardiovascular and neoplastic diseases and therefore can be responsible for low levels of self-esteem.

Thus, in this paper to conduct our validation we used Rosenberg's definition (1960) which reports that self-esteem is the positive or negative reflection an individual has of himself. Apart from validating RSES we will also correlate RSES with a new tool of Darviri and Varvogli a self-esteem questionnaire, to examine if the second measures self-esteem. We will then correlate self-esteem with perceived stress scale, where we hypothesize that these two factors have a negative relationship to each other, then examine self-esteem and health locus of control, where we expect that these factors have a positive outcome, and thirdly we will test self-esteem with personality where in this case we expect too, to have a positive relation. All of these measures were made in order to reinforce the questionnaire's validity.

\section{Method}

\subsection{Sample}

Our sample consists of 652 individuals, students who completed the questionnaires. Our demographic data showed that out of the 652 participants $51.4 \%$ were male and $48.6 \%$ female. The largest number of people lives permanently in Attica, with a percentage of 50.6\%, 5.4\% are residents of Larissa, $4.2 \%$ are residents of Thessaloniki and 3.7\% are residents of Volos. The remaining 39\% of our sample are residents almost all other cities in the country.

As to the age, $38.64 \%$ are from 20 to 21 years old, $34.50 \%$ are from 18 to 19 years old, $10.11 \%$ are from 22 to 23 years old, 5.05\% are from 24 to 25 years old and finally $11.65 \%$ are over 26 years old. $88 \%$ of the participants were undergraduate students, which is consistent with the young ages, while the rest $12 \%$ of participants were postgraduate students, therefore the older age.

\subsection{Tools}

1) Survey participants filled out a demographic data with scales, such as age, sex, origin and education level.

2) Rosenberg Self-Esteem Scale. It consists of 10 questions rated on a Likert scale from 1 - 4 having 1 to strongly disagree, 2 disagree, 3 agree and 4 strongly agree.

3) Perceived Stress Scale 14, validated in Greek by Andrew E. and associates. Consists of 14 Likert type 
questions from $1-5$, where 1 = never, 2 = almost never, $3=$ sometimes, $4=$ fairly often and $5=$ very often.

4) Health Locus of Control already validated in the Greek language. Consists of 18 questions Likert type scale, where 1 = very strongly disagree, 2 = disagree to some extent, 3 = slightly disagree, 4 = agree slightly, 5 = agree to some degree and $6=$ agree very much. It has 3 subcategories with 6 questions for each of them. Subcategory internal with questions $1,6,8,12,13,17$, chance to questions $2,4,9,11,15,16$, and personal others with questions 3, 5, 7, 10, 14, 18. Each subclass is independent of the other and can score 6 - 36.

5) Personality and Stress Self-Test with 20 questions to seven-class scale, in which according to the individual's score is ranked in one of the four subclasses. Subtype B (score 0 - 29) individuals are loose and deal well with stress; it is unlikely to develop any illness associated with stress. Subtype B + (score 30 - 59) individuals are generally loose and adequately address stress. Subcategory AB (score 60 - 79) in this category have a mixture of A and B. It is a healthy standard, but people are able to sneak in a negative for the organism behavior, and should be able to recognize this. Subcategory A (score 80 - 109) individuals are susceptible to the occurrence of heart disease and should take strong measures to reduce stress. Subcategory A + (score 110 - 140) people in this category, especially if they are over 40 years old and tobacco users are likely to have a high risk of developing heart disease and should take strong measures to reduce stress.

6) Finally, Self-esteem Questionnaire from Darviri and Varvogli with 59 questions with five-point Likert type scale, where 1 = never, 2 = almost never, 3 = sometimes, 4 = fairly often and $5=$ very often.

\subsection{Process}

Translation. The translation of the questionnaire was done by two different people that know English. Initially the questionnaire was translated into Greek from one person and then from the other one the Greek form was translated in English. We processed the questionnaire for the correct syntax and questions' rendition in Greek language and end up in a sample of thirty (30) persons to see if it is understood and can be easily reached. Following the observations of the sample, we did some editorial changes which were the last before the beginning of our research.

Our sample consists of undergraduate and graduate students of Greek universities, with majors on health sciences and humanities. The questionnaires were given according to the class professor at the beginning or end of the teaching period and were anonymous. The researcher gave the instructions, before people starting to fill in the questionnaires, was present in the process for any questions and oversaw copying or randomly completing the questionnaires.

From this process the number of our sample was up to 683 people, of which 6 were of other nationalities and 15 did not complete the questionnaire or did it in luck. Our final sample consisted of 652 individuals who completed the questionnaires. In our statistical analysis we excluded the individuals that did not answer all 10 questions of RSES, in order to have more reliable results.

\section{Results}

From our statistical analysis we used the processor SPSS 20.0.

Our descriptive statistics depict that most of subjects' responses, primarily present the median prices, while systematically avoid the extreme answers. Additionally we see that the total variance of questions ranges from .2 up to .6 (Table 1).

\subsection{Correlation}

Table 2 shows the coherence of RSES questions which ranges between .12 and .47 . The correlation is statistically significant as sig $=.00<.05$. It is also positive which means that all questions count the same dimension. The coherence between questions is positive between $.2-.6$ based on methodological rule and an indication that all questions count the same direction (the reverse has been done before rating) and are related to each other, therefore count the same dimension, without repeating of one another with affinities of .7 and above.

\subsection{Reliability Analysis}

Subsequently, to test the reliability of the questionnaire we used the analysis of Cronbach Alpha ( $\alpha$ ). This analysis showed high reliability of the tool, since the index had a value of .809 which is greater than .7 required for 
the overall reliability of each tool. We applied Guttmann's analysis of split half and again the reliability of our tool reached .791. From Table 3 we can ascertain that we cannot eliminate any question as the reliability of our questionnaire will decrease. From foreign language validations we can also see that in Spain and for Spanish language the reliability of the questionnaire is .85 (Martín-Albo, Nunez, Navarro, \& Grijalvo, 2007) and in Canada for French language is .70 (Vallieres \& Vallerand, 1990).

\subsection{Validity Based on Demographic Criteria}

By conducting descriptive statistics, we saw that women scored higher in self-esteem than men. More specific, women had mean of 20.01 and st. deviation 4.20 while men had mean of 18.48 and st. deviation 3.82. In our sample as shown in Table 4, women appear to have higher self-esteem than men where sig $=.00<.05$ therefore it is statistically important, a fact inconsistent with the literature, where it seems that women have lower self-esteem than men (Martín-Albo, Nunez, Navarro, \& Grijalvo, 2007).

\subsection{Validity Criteria}

In order to examine the validity criterion we tested our questionnaire (RSES) with the other questionnaires given to our subjects.

\section{Table 1. Descriptive statistics.}

\begin{tabular}{ccccccc}
\hline & $\mathrm{N}$ & Mean & Std. deviation & Variance & \multicolumn{2}{c}{ Skewness } \\
\hline & Statistic & Statistic & Statistic & Statistic & Statistic & Std. error \\
\hline Rosenberg 1 & 651 & 1.82 & .542 & .294 & .018 & .096 \\
Rosenberg 2 & 649 & 2.40 & .731 & .534 & -.003 & .096 \\
Rosenberg 3 & 650 & 1.93 & .509 & .259 & .165 & .096 \\
Rosenberg 4 & 649 & 1.77 & .640 & .410 & .419 & .096 \\
Rosenberg 5 & 649 & 1.99 & .745 & .555 & .469 & .096 \\
Rosenberg 6 & 652 & 1.98 & .796 & .634 & .243 & .096 \\
Rosenberg 7 & 650 & 1.65 & .616 & .380 & .474 & .096 \\
Rosenberg 8 & 651 & 2.26 & .831 & .690 & .330 & .096 \\
Rosenberg 9 & 651 & 1.60 & .701 & .492 & .996 & .096 \\
Rosenberg 10 & 652 & 1.84 & .590 & .348 & .233 & .096 \\
\hline
\end{tabular}

Table 2. RSES and item correlations.

\section{Rosenberg 1}

\begin{tabular}{|c|c|c|c|c|c|c|c|c|c|}
\hline Rosenberg 2 & .262 & Rosenberg 2 & & & & & & & \\
\hline Rosenberg 3 & .314 & .166 & Rosenberg 3 & & & & & & \\
\hline Rosenberg 4 & .302 & .091 & .383 & Rosenberg 4 & & & & & \\
\hline Rosenberg 5 & .253 & .345 & .296 & .305 & Rosenberg 5 & & & & \\
\hline Rosenberg 6 & .322 & .465 & .14 & .17 & .383 & Rosenberg 6 & & & \\
\hline Rosenberg 7 & .293 & .153 & .268 & .466 & .353 & .172 & Rosenberg 7 & & \\
\hline Rosenberg 8 & .245 & .29 & .122 & .181 & .301 & .31 & .185 & Rosenberg 8 & \\
\hline Rosenberg 9 & .393 & .274 & .145 & .36 & .473 & .468 & .387 & .421 & Rosenberg 9 \\
\hline Rosenberg 10 & .337 & .274 & .211 & .296 & .352 & .371 & .314 & .286 & .464 \\
\hline
\end{tabular}


Table 3. RSES reliability-item-total statistics.

\begin{tabular}{lccccc}
\hline & $\begin{array}{c}\text { Scale mean if item } \\
\text { deleted }\end{array}$ & $\begin{array}{c}\text { Scale variance if item } \\
\text { deleted }\end{array}$ & $\begin{array}{c}\text { Corrected item-total } \\
\text { correlation }\end{array}$ & $\begin{array}{c}\text { Squared multiple } \\
\text { correlation }\end{array}$ & $\begin{array}{c}\text { Cronbach’s alpha if } \\
\text { item deleted }\end{array}$ \\
\hline Rosenberg 1 & 17.42 & 14.378 & .487 & .272 & .789 \\
Rosenberg 2 & 16.83 & 13.813 & .430 & .281 & .238 \\
Rosenberg 3 & 17.30 & 15.048 & .351 & .395 & .801 \\
Rosenberg 4 & 17.46 & 14.158 & .439 & .355 & .793 \\
Rosenberg 5 & 17.25 & 13.098 & .566 & .374 & .778 \\
Rosenberg 6 & 17.26 & 13.045 & .523 & .309 & .784 \\
Rosenberg 7 & 17.59 & 14.196 & .455 & .223 & .791 \\
Rosenberg 8 & 16.97 & 13.382 & .429 & .478 & .797 \\
Rosenberg 9 & 17.63 & 12.982 & .640 & .300 & .769 \\
Rosenberg 10 & 17.39 & 13.979 & .533 & & .784 \\
\hline
\end{tabular}

Table 4. RSES and sex differences.

\begin{tabular}{cccccc}
\hline & Sum of squares & df & Mean square & F & Sig. \\
\hline Between groups & 371.916 & 1 & 371.916 & 16.129 & .000 \\
Within groups & 10290.395 & 638 & & \\
Total & 10662.311 & 639 & & \\
\hline
\end{tabular}

From these results (Table 5) we concluded that PSS with RSES seem to have a positive affinity $p=.481$ and statistically significant sig $=.00<.05$, therefore when stress increases, self-esteem of people also increases. PSS with our own self-esteem questionnaire also has a positive affinity $p=.538$ and statistically significant sig $=.00$ $<.05$, which gives us the same results as the RSES, meaning that increasing stress increases, self-esteem.

The internal subscale of HLC with RSES have a negative affinity $p=-.154$ and statistically significant sig $=.00<.05$, so the more people attach their good health to themselves, the lower is their self-esteem. The same applies to the second self-esteem questionnaire where $p=-.123$ and sig $=.003<.05$. The subscale chance for the RSES $p=.41$ and sig $=.022<.05$ and the self-esteem questionnaire Darviri and Varvogli $p=.177$ and sig $=.00<.05$, which means that the more we attribute health to our own luck, the more increases our self-esteem. The subscale personal others of HLC with RSES have a $p=.062$ and sig $=.125>.05$, and self-esteem questionnaire of Darviri and Varvogli have a $p=.056$ and sig $=.172$ which means that their relation is positive but with no statistical significance.

The personality type questionnaire with RSES and our questionnaire of self-esteem have a positive correlation with $p=.243$ and $p=.284$ respectively. Also, the relationship is statistically significant sig $=.00<.05$ for both questionnaires, which means that when self-esteem is increased, the more individuals score at high risk personality types. Finally both self-esteem questionnaires have positive affinity $p=.704$ and statistically significant sig $=.00<.05$, therefore both these tools measure the same factor, self-esteem.

\subsection{Construct Validity}

Finally we conducted a principal component analysis with oblimin rotation. First we saw on the KMO and Bartlett's test that our sample is sufficient to continue our analysis $(.842>.5)$ and statistically significant $(.00<.05)$. The test suggested that the questionnaire's structure is divided into two factors correlated to each other. Table 6 also shows the variables each factor correlates with. More specifically, the reversed questions (2, 5, 6, 8 and 9) and the last question (10) are associated to each other and construct Factor 1. On the other hand Factor 2 consists of the positive questions (1, 3, 4 and 7). Moreover in the Figure 1 there is also a clustering of data, where plainly appear again two factors. 
Table 5. Convergent validity.

\begin{tabular}{ccccccc}
\hline & Pss total & Hloc internal & Hloc chance & Hlocpers others & Personality & Self total \\
\hline Pearson correlation & $.481^{* *}$ & $-.154^{* *}$ & $.091^{*}$ & .062 & $.243^{* *}$ & $.704^{* *}$ \\
Sig. (2-tailed) & .000 & .000 & .022 & .125 & .000 & .000 \\
N & 640 & 633 & 633 & 623 & 603 & 597 \\
\hline
\end{tabular}

${ }^{* *}$ Correlation is significant at the .01 level (2-tailed). ${ }^{*}$ Correlation is significant at the .05 level (2-tailed).

\section{Table 6. Factor structure.}

\begin{tabular}{|c|c|c|}
\hline & \multicolumn{2}{|c|}{ Component } \\
\hline & 1 & 2 \\
\hline Rosenberg 1 & & .521 \\
\hline Rosenberg 2 & .693 & \\
\hline Rosenberg 3 & & .666 \\
\hline Rosenberg 4 & & .806 \\
\hline Rosenberg 5 & .623 & \\
\hline Rosenberg 6 & .778 & \\
\hline Rosenberg 7 & & .735 \\
\hline Rosenberg 8 & .625 & \\
\hline Rosenberg 9 & .722 & \\
\hline Rosenberg 10 & .608 & \\
\hline
\end{tabular}

Extraction method: principal component analysis. Rotation method: Oblimin with kaiser normalization.

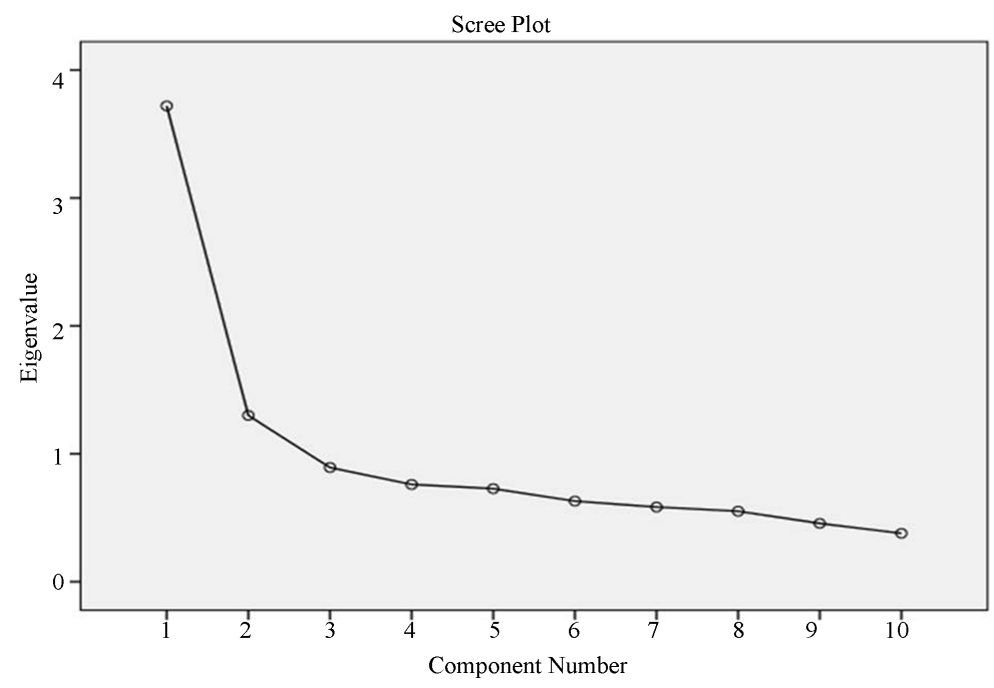

Figure 1. Factor clustering.

\section{Discussion}

From our statistical processing we conclude that the relationship between self-esteem and health locus of control is statistically significant only in two of the three subcategories of the questionnaire. It seems that when people let their health to others or to chance, have an increased self-esteem in comparison to those who believe their good health is monitored by themselves.

Stress seems to have a relation with self-esteem. The statistical analysis shows that we have a positive and 
statistically significant relation. We see that self-esteem does not reduce stress but seems to have a relation of increase. The higher the level of self-esteem, the greater is the stress experienced by the individual.

According to literature, Baumeister, Smart and Boden (1996) report that in their research on self-esteem and its relation to academic performance, individuals of high academic performance had high self-esteem. Low achievers had low self-esteem. So it seems that it is not self-esteem that pushes people to perform better, but the satisfaction of a good mark increases their self-esteem and gives them value. Researchers also reported that self-esteem decreases when the self-concept of the individual is important for his academic performance in order to compose his character.

On the basis of our analyses, when stress increases, self-esteem increases as well and when self-esteem increases, stress also increases. This could be attributed to individuals' overexertion.

Self-esteem is an acquired characteristic which is enhanced by behaviors such as good academic performance. The higher the performance, the better the person feels. On the contrary, when shaken, so is the overall emotional assessment of the value of the individual. So, when our physical integrity is threatened by a stimulus, the body becomes stressed and we follow the "fight or flight" model (Mash \& Johnston, 1983). In the same way, the students in our study have high levels of stress because when their self-esteem is under threat, they react to bring it back. In the academic community, therefore, the maintenance of self-esteem is a constant battle, in which individuals are constantly judged, leading to high levels of stress.

\section{Conclusion}

The main purpose of this research was to translate and validate the Rosenberg self-esteem questionnaire in the Greek language.

Our results showed that the reliability of the questionnaire was high. Its internal consistency was efficient and supported by the test's reliability. On the basis of validity criteria we concluded that it has a significant and positive relation with the Greek self-esteem questionnaire by Darviri and Varvogli, meaning that both questionnaires do measure self-esteem. Nevertheless we cannot refer to the Greek self-esteem questionnaire because it has not been validated in Greek. Nonetheless we cannot refer to self-esteem questionnaire by Darviri and Varvogli because it has not been validated in Greek language.

The results from the differences in gender, in general, showed a higher arithmetic mean of self-esteem for women and lower for men, which is the opposite result from the Spanish validity (Vallieres \& Vallerand, 1990), but in accordance with the French (Miller \& Ross, 1975). These differences could be explained by socio-cultural factors.

As Greenberger et al. (2003) and Prezza et al. (1997), we found a two-factor model, which seems to better explain the dimension of self-esteem. In our research we reversed the negative questions, therefore we found two factors, opposite to other researchers who found one factor when validated the same questionnaire (Martín-Albo, Nunez, Navarro, \& Grijalvo, 2007). These two factors are related to each other and measure self-esteem. Summarizing, our validation confirms a two-factor model of RSES.

\section{References}

Abouserie, R. (1994). Sources and Levels of Stress in Relation to Locus of Control and Self-Esteem in University Students. Educational Psychology, 14, 323-330. http://dx.doi.org/10.1080/0144341940140306

Baumeister, F. (2005). Rethinking Self-Esteem. Why Nonprofits Should Stop Pushing Self-Esteem and Start Endorsing SelfControl. Stanford Social Innovation Review, 2005, 1-9.

Baumeister, R. F., Smart, L., \& Boden, J. M. (1996). Relation of Threatened Egotism to Violence and Aggression: The Dark Side of High Self-Esteem. Psychological Review, 103, 5-33. http://dx.doi.org/10.1037/0033-295X.103.1.5

Branden, N. (1969). The Psychology of Self-Esteem. New York: Bantam.

Branden, N. (2001). The Psychology of Self-Esteem: A Revolutionary Approach to Self-Understanding That Launched a New Era in Modern Psychology. San Francisco: Jossey-Bass.

Cannon, W. B. (1926). Physiological Regulation of Normal States: Some Tentative Postulates Concerning Biological Homeostatics. Paris: Editions Medicales.

Carlson, N. R. et al. (2007). The Science of Behaviour. Toronto, ON: Pearson Education.

Friedman, M., \& Roseman, R. (1959). Association of Specific Overt Behaviour Pattern with Blood and Cardiovascular Findings. Journal of the American Medical Association, 169, 1286-1296.

http://dx.doi.org/10.1001/jama.1959.03000290012005 
Gana, K., Alaphilippe, D., \& Baillo, D. (2005). Factorial Structure of the French Version of the Rosenberg Self-Esteem Scale among the Elderly. International Journal of Testing, 5, 169-176. http://dx.doi.org/10.1207/s15327574ijt0502_5

Greenberger, E., Chen, Ch., Dmitrieva, J., \& Farruggia, S. P. (2003). Item-Wording and the Dimensionality of the Rosenberg Self-Esteem Scale: Do They Matter? Personality and Individual Differences, 35, 1241-1254. http://dx.doi.org/10.1016/S0191-8869(02)00331-8

Grossarth-Maticek, R., Eysenck, H. J., \& Vetter, H. (1988). Personality Type, Smoking Habit and Their Interaction as Predictors of Cancer and Coronary Heart Disease. Personality and Individual Differences, 9, 479-495. http://dx.doi.org/10.1016/0191-8869(88)90125-0

Hensley, W. E., \& Roberts, M. K. (1976). Dimensions of Rosenberg’s Self-Esteem Scale. Psychological Reports, 38, 583584. http://dx.doi.org/10.2466/pr0.1976.38.2.583

Hewitt, J. P. (2009). Oxford Handbook of Positive Psychology (pp. 217-224). Oxford: Oxford University Press.

Kliewer, W., \& Sandler, I. N. (1992). Locus of Control and Self-Esteemas Moderators of Stressor-Symptom Relations in Children and Adolescents. Journal of Abnormal Child Psychology, 20, 393-413. http://dx.doi.org/10.1007/BF00918984

Marsh, H. W. (1990). The Structure of Academic Self-Concept: The Marsh/Shavelson Model of Educational Psychology. Journal of Educational Psychology, 82, 623-636.

Marsh, H. W. (1996). Positive and Negative Self-Esteem: A Substantively Meaningful Distinction or Artifactors? Journal of Personality and Social Psychology, 70, 810-819. http://dx.doi.org/10.1037/0022-3514.70.4.810

Martín-Albo, J., Nïpez, J. L., Navarro, J. G., \& Grijalvo, F. (2007) The Rosenberg Self-Esteem Scale: Translation and Validation in University Students. The Spanish Journal of Psychology, 10, 458-467.

Mash, E. J., \& Johnston, C. (1983). Parental Perceptions of Child Behavior Problems. Parenting Self-Esteem, and Mothers' Reported Stress in Younger and Older Hyperactive and Normal Children. Journal of Consulting and Clinical Psychology, 51, 86-99. http://dx.doi.org/10.1037/0022-006X.51.1.86

Maslow, A. H. (1987). Motivation and Personality (3rd ed.). New York: Harper \& Row.

Miller, D. T., \& Ross, M. (1975). Self-Serving Biases in the Attribution of Causality, Factor or Fiction? Psychological Bulletin, 82, 213-225. http://dx.doi.org/10.1037/h0076486

Motl, R. W., \& DiStefano, C. (2002). Longitudinal Invariance of Self-Esteem and Methods Effects Associated with Negatively Worded Items. Structural Equation Modeling, 9, 562-578. http://dx.doi.org/10.1207/S15328007SEM0904_6

Newman, B. M., \& Newman, P. R. (1975). Development through Life: A Psychosocial Approach. Homewood, IL: Dorsey.

Olsen, J. M., Breckler, S. J., \& Wiggins, E. C. (2008). Social Psychology Alive. Ontario: Nelson.

Prezza, M., Trombaccia, F. R., \& Armento, L. (1997). La scala dell’autostima di Rosenberg: Traduzione e validazioneitaliana. Bollettino di Psicologia Applicata, 223, 35-44.

Rosenberg, M. (1965). Society and the Adolescent Self-Image. Princeton, NJ: Princeton University Press.

Schacter, D. L., Gilbert, T. G., \& Wegner, M. D. (2010). Psychology Study Guide. London: Worth Publishers.

Smith, E. R., \& Mackie, D. M. (2007). Social Psychology. New York: Psychology Press.

Vallieres, E. F., \& Vallerand, R. J. (1990). Traduction et validation Canadienne-Francaise se l'echelle de l'estime de soi de Rosenberrg. International Journal of Psychology, 25, 305-316. http://dx.doi.org/10.1080/00207599008247865

Wang, J., Siegal, H. A., Falck, R. S., \& Carlson, R. G. (2001). Factorial Structure of Rosenberg's Self-Esteem Scale among Crack-Cocaine Drug Users. Structural Equation Modeling, 8, 275-286. http://dx.doi.org/10.1207/S15328007SEM0802 6

Willburn, V. R., \& Smith, D. E. (2005) Stress Self-Esteem and Suicidal Ideation in Late Adolecents. Adolecence, 40 , 33-45. 